\title{
Earthworm-assisted bioremediation of petroleum hydrocarbon contaminated soil from mechanic workshop
}

\author{
Ameh A. O. ${ }^{1 *}$, Mohammed-Dabo I. A. ${ }^{1}$, Ibrahim S. ${ }^{2}$ and Ameh J. B. ${ }^{3}$ \\ ${ }^{1}$ Department of Chemical Engineering, Ahmadu Bello University, Zaria 810261, Kaduna State, Nigeria. \\ ${ }^{2}$ Department of Biochemistry, Ahmadu Bello University, Zaria, Kaduna State, Nigeria. \\ ${ }^{3}$ Department of Microbiology, Ahmadu Bello University, Zaria, Kaduna State, Nigeria.
}

Accepted 12 June, 2013

\begin{abstract}
The use of earthworms (Eudrilus eugenia) for vermi-assisted bioremediation of petroleum hydrocarbon contaminated mechanic workshop soils was investigated. Parameters of interest where earthworm survival, microbial count and identification, carbon and nitrogen contents of the soil and total petroleum hydrocarbon content of the soil. Earthworm survival was found to be dependent on the concentration of petroleum hydrocarbon and nature of the mechanic workshop. The survival of the worms in the as-obtained mechanic workshop soil was much lower than the survival in mechanic workshop soil diluted with petroleum hydrocarbon free soil. Earthworm inoculation also resulted in lower soil $\mathbf{C}$ and $\mathbf{N}$ contents after 35 days of vermi-assisted bioremediation. After 35 days of treatment, earthworm inoculation effected a higher drop in total petroleum hydrocarbon contents as compared to the samples without worms, indicating that earthworms may be used as biocatalysts in the bioremediation process.
\end{abstract}

Key words: Eudrilus eugeniae, total petroleum hydrocarbon, mechanic workshop soil.

\section{INTRODUCTION}

The quality of life on earth is linked, inextricably, to the overall quality of the environment. Releases of persistent, bioaccumulative and toxic chemicals have a detrimental impact on human health and the environment. Contaminated lands generally result from past industrial activities when awareness of the health and environmental effects connected with the production, use, and disposal of hazardous substances were less recognized than today (Vidali, 2001). The problem is worldwide, but more severe in the developing countries where there were no effective regulatory policies on the environment. Petroleum contaminants are typical examples of these hazardous constituents. Soil contaminated with petroleum products can be defined as any earthen material or artificial fill that has human or natural alteration of its physical, chemical, biological or radiological integrity resulting from the introduction of crude oil, any fraction or derivative thereof (such as gasoline, diesel or motor oil), or oil-based product (Dhanasekaran et al., 2009; Chukwuma et al., 2010; Refaat, 2010).

The problems associated with used engine oil (UEO) are mainly as a result of poor management. In most developing countries, oil spills at auto-mechanic workshops have been left uncared for over the years and its continuous accumulation is of serious environmental concern because of the hazard associated with it. For instance, spent motor oil disposed improperly contains potentially toxic substances such as benzene (carcino- 
gens), lead, arsenic, zinc and cadmium, which can seep into the water table and contaminate ground water (Igwe et al., 2008; Shah et al., 2009). It consequently results in serious health hazard such as anemia and tremors, which can cause death. If used motor oil and the contaminants it contains are disposed of inappropriately and released into the environment, they can harm humans, plants, animals, fish and shellfish. In water, oil is a visible pollutant, floating as a scum on the surface. This oil scum can stop sunlight and oxygen from getting into the water, affecting fish and water plants. It can kill fish, frogs and other animals that breathe from the water's surface. According to USEPA (1996), a liter of used engine oil is enough to contaminate one million gallons of freshwater.

Physicochemical technologies including thermal treatment, dig and dump method, chemical method, separation techniques and stabilization/solidification technology have been used for ages for the treatment or disposal of soils contaminated with petroleum products. Some of the limitations of these methods include: they are expensive to implement at full scale, they are not environmentally friendly, their technologies are complex and they lead to destruction of soil texture and characteristics (Zhang et al., 2009) and do not always result in complete neutralization of pollutants (Yerushalmi et al., 2003). Due to limitations of the physicochemical technologies, great deals of literature have reported that bioremediation technologies are alternatives and or supplements to these technologies. This is because of their cost effectiveness, environmental friendliness, simplicity in technology and conservation of soil texture and characteristics (Vidali, 2001; Yerushalmi et al., 2003; Adams and Guzman-Osorio, 2008; Fouépé et al., 2009). Bioremediation of petroleum hydrocarbons suffers mass transfer limitations as a result of the high hydrophobicity and low solubility of the contaminants in aqueous media (Li et al., 1995). This makes bioremediation a very slow process.

Earthworms are terrestrial annelids with bilateral symmetry. They are important factors in the development of soil structure, organic matter breakdown and nutrient cycling. Generally, the activities of earthworm are considered to improve soil health and theoretically can translate to improved bioremediation. In spite of the numerous ways in which the activities of earthworm promotes soil health, relatively few research have been undertaken to study the effects of earthworm on petroleum hydrocarbons contamination removal from soil (Hickman and Reid, 2008). Schaefer and Juliane (2007) concluded that earthworms may trigger the degradation process and might therefore, be applied in the remediation of oil contaminated soil with moderate TPH concentrations. Schaefer et al. (2005) reported that earthworms can contribute positively to bioremediation of oilcontaminated soil, but that the effect may be speciesdependent. Ameh et al. (2011a) reported the survival of earthworms (Eudrilus eugeniae) in used engine oil (from automobiles) contaminated soil. They reported that used engine oil concentration level tolerable to earthworms was dependent on the source of the used engine oil. Ameh et al. (2011b) investigated the effect of earthworm on the bioremediation of simulated used-engine oilcontaminated soil and reported that the presence of earthworms can influence the rate of bioremediation of used engine contaminated soil, given right conditions.

The objective of this study was to examine the ability of earthworm ( $E$. eugeniae) to enhance the bioremediation of spent engine oil contaminated soil, making a comparison between biostimulation and vermi-assisted bioremediation.

\section{MATERIALS AND METHODS}

\section{Procurement and preparation of materials}

Soil samples from two types of mechanic workshops were considered for this investigation: motorcar and motorcycle mechanic workshops (MM and $\mathrm{MC}$, respectively). Large particles (metal, gravels and sticks) were removed from the soil samples. Two TPH contents of the soils were considered $(92.73$ and $31.61 \mathrm{~g}$ oil/kg soil for MM and 138.18 and $69.27 \mathrm{~g} \mathrm{oil} / \mathrm{kg}$ soil for MC). The larger portion of the TPH contaminated soil was soil as obtained from mechanic workshop whereas the smaller of the two TPH values for both mechanic workshop soils considered was obtained by diluting the mechanic workshop soil with petroleum hydrocarbon free soil obtained from Samaru, Zaria. The water holding capacity of the undiluted and diluted soil samples was determined thus: six (6) inches of soil was placed in percolation tube and compacted by gentle bouncing. Water was added until the water level stood at about 2 inches above soil level. The tube was covered and left to stand for 2 days. After this period, the top half-inch of soil was discarded and wet soil was weighed into a pre-weighed evaporating dish. The sample was placed in oven at $110^{\circ} \mathrm{C}$ for $24 \mathrm{~h}$. It was then removed and weighed to obtain bone dry weight of the sample. Percent water holding capacity was calculated as (Srivastava and Thakur, 2006):

$\%$ water holding capacity $(\mathrm{WHC})=\frac{\text { wet weight }- \text { bone dry weight }}{\text { bone dry weight }} * 100$

Cassava tubers where obtained from Samaru market and identified in the Biological Science Department of Ahmadu Bello University, Zaria. The cassava used was identified as Manihot esculenta (Crantz). The tubers were peeled and the peels soaked in water for a period of one week to allow for detoxification of any cyanohydrin which might be present. After decantation, the fermented cassava peels were then dried in an oven at $30^{\circ} \mathrm{C}$ for four days. The dried peels were then crushed and sieved using $5 \mathrm{~mm}$ sieve mesh. Cassava peels was prepared for use as organic amendment.

Earthworms were obtained from Samaru village Zaria and identified as $E$. eugeniae. The worms were collected along with the soil in which they were found and kept for $24 \mathrm{~h}$ before use in clean plastic containers.

\section{Preparation of samples}

$500 \mathrm{~g}$ of the mechanic workshop soil was placed in a plastic container and deionized water was added to $60 \%$ water holding capacity and then thoroughly mixed manually. $50 \mathrm{~g}$ of fermented cassava peels was then added and again mixed. A second sample 
was similarly prepared to which 10 earthworm were in addition introduced. Both samples were covered with muslin cloth to prevent the worms escaping from the sample with worms. All samples were studied for 35 days. This procedure was repeated for the mechanic workshop soil diluted with petroleum hydrocarbon free soil. This was done for the motorcar mechanic workshop soil as well as the motorcycle mechanic workshop soil in turns. Control samples for each case (diluted and undiluted) were also prepared. The control sample had neither organic amendment nor earthworms. All samples were prepared in duplicates and maintained at $60 \%$ water holding capacity throughout the period of the study. Starting from day zero and then every week, the TPH of all samples was followed using a gravimetric method (Adesodun and Mbagwu, 2008): ten grams of soil was collected and dried at room temperature for $72 \mathrm{~h}$. Five grams of the soil was placed in 200 milliliters beaker into which was added 150 milliliters of toluene. The mixture was stirred continuously for $30 \mathrm{~min}$, left to stand in a fume cupboard for $2 \mathrm{~h}$ and then filtered using Whatman No 42 filter paper. The residue, soil, was allowed to dry in an oven at $50^{\circ} \mathrm{C}$. TPH was computed as:

$\operatorname{TPH}(\mathrm{g} / \mathrm{kg})=\frac{\text { (initial weight of soil }- \text { weight of soil after solvent extraction) ing }}{\text { Initial weigh of soil in } \mathrm{kg}}$

The composition of the petroleum hydrocarbon contaminant was determined by mixing two grams of dry contaminated soil (at time, $t$ $=0$ ) with $5 \mathrm{ml}$ of dichloromethane and analyzing the supernatant after settling using GCMS (GCMS-QP2010 Plus Shimadzu, Japan). The initial column oven temperature was kept at $60^{\circ} \mathrm{C}$ for five minutes and then raised by $20^{\circ} \mathrm{C}$ per minute to $140^{\circ} \mathrm{C}$ and then at $5^{\circ} \mathrm{C}$ per minute to $200^{\circ} \mathrm{C}$. It was held at $200^{\circ} \mathrm{C}$ for $5 \mathrm{~min}$ and then raised by $4^{\circ} \mathrm{C}$ per minute to $280^{\circ} \mathrm{C}$. The total run time was $49 \mathrm{~min}$.

\section{Earthworm metal uptake and elimination}

Elemental analysis using EDXRF (MiniPal PW4025, Philips Analytical) of soil samples at the start and finish was conducted also on the earthworms samples at the start and after 35 days of inoculation (for the samples for which the worms were still alive). Procedure was coined from OECD (2010). On the set days, 0 and 35 , the worms were removed from the soil and placed on a filter paper wetted with distilled water in a flat plastic bowl. The worms were thus kept, on the wet filter paper, for $48 \mathrm{~h}$ to void their gut content after which they were quickly killed by placing on ice and their carcasses dried in an oven at $35^{\circ} \mathrm{C}$ for $48 \mathrm{~h}$. The dried carcasses were then analyzed for metal content using EDXRF. The elemental composition of the soil samples were also determined by EDXRF analysis of the dried soil (at $30^{\circ} \mathrm{C}$ for $72 \mathrm{~h}$ ) samples.

\section{Effect on soil carbon and nitrogen content}

On day $35,10 \mathrm{~g}$ of soil was collected from each sample and the carbon and nitrogen contents were determined using the WalkleyBlack (AOAC, 1990) and the Macro-Kjedahl (AOAC, 1990) methods, respectively.

\section{Microbial count and identification}

Microbial count and identification was conducted on the soil samples obtained from mechanic workshops (before treatment with organic amendment or earthworms) as well as on all diluted samples (motorcycle and motorcar, worms treated and worms free). Twenty five grams $(25 \mathrm{~g})$ of soil sample was mixed with $225 \mathrm{ml}$ of normal saline $(\mathrm{NaCl}+\mathrm{H} 2 \mathrm{O})(1: 10)$. Ten fold dilution were then prepared, that is $1 \mathrm{ml}$ of the diluted sample (stock) was transferred into $9 \mathrm{ml}$ of sterile normal saline $\left(10^{1}\right)$ by using a sterile pipette, this was repeated to obtain $10^{2}, 10^{3}, 10^{4}$ and $10^{5}$ dilutions, respectively. Using a sterile pipette, 0.1 milliliters of $10^{3}, 10^{4}$ and $10^{5}$ dilution was aseptically transferred into sterile plate count agar (PCA) plates in duplicates. With the aid of a sterile bend glass rod, the inoculum was spread on the surface of the culture medium (PCA). The inoculated plates were incubated at $37^{\circ} \mathrm{C}$ for $24 \mathrm{~h}$. The isolates were Gram stained and observed under the microscope to determine the gram reaction, morphology and the presence of spores. The organisms were identified and characterized. Gramreaction, motility, shape and color of colony, catalase and oxidase activities were checked.

\section{RESULTS}

Table 1 presents the result of percentage TPH decrease and earthworm survival after 35 days of bioremediation for biostimulated and vermi-assisted systems.

Figures 1 and 2 presents the result of the fit of the bioremediation data obtained from the mechanic workshop soil samples (motorcar mechanic workshop soil and motorcycle mechanic workshop soil, respectively) to the $1^{\text {st }}$ order bioremediation kinetics (Yeung et al., 1990; Adesodun and Mbagwu, 2008).

Figures 3 and 4 presents the GC chromatogram of the diluted motorcycle mechanic workshop soil at the beginning and end of the study, whereas Table 2 presents the result of the MS comparison. Table 3 presents the microbial count and identification of the samples on day 35 .

Table 4 presents the result of the analysis of carbon and nitrogen contents of the treated soil samples. Table 5 presents the result of metal uptake and elimination by the worms in the 35 day study.

\section{DISUSSION}

For soil from both types of mechanic workshop considered, the use of earthworm inoculation proved to have an effect on the rate of degradation of petroleum hydrocarbon as shown in Table 1. All the samples treated with worms had higher drops in TPH than the corresponding control samples (without worms). The least effect was observed for the MCU samples (undiluted soil from motorcycle mechanic workshop) in which earthworm survival dropped to $0 \%$ (all the worms died) in less than $24 \mathrm{~h}$. There was only a marginal difference recorded between the MCU and the control (24.26461 and 24.56509, respectively).

It may also be observed that the highest drops in TPH for both mechanic workshop soil samples was recorded in the earthworm treated dilute samples (44.18 and $39.10 \%$ for MC and MM, respectively). Incidentally, these samples recorded an appreciable survival of earthworm over the duration of the study: on day 35, MCDW recorded $70 \%$ earthworm survival whereas MMDW recorded $80 \%$ survival of the earthworms.

For the undiluted soil samples (UD), MCUW recorded 
Table 1. Effect of earthworm inoculation on the bioremediation of petroleum hydrocarbon contaminated soil from mechanic workshops.

\begin{tabular}{lccc}
\hline \multicolumn{5}{c}{ Initial TPH (g/kg) } & TPH Decrease after 35 days (\%) & Earthworm survival after 35 days (\%) \\
\hline \multicolumn{2}{l}{ Soil from } \\
MMUNorcar mechanic workshop & 92.73 & 34.96694 & \\
MMUW & 92.73 & 36.3521 & 30 \\
MMDNW & 31.61 & 29.49738 & 80 \\
MMDW & 31.61 & 39.09603 & \\
\multicolumn{5}{c}{} \\
Soil from motorcycle mechanic workshop \\
MCUNW & 138.18 & 24.56509 & 0 \\
MCUW & 138.18 & 24.26461 & \\
MCDNW & 69.27 & 28.8435 & 70 \\
MCDW & 69.27 & 44.17804 & \\
\hline
\end{tabular}

MMUW: Undiluted motorcar mechanic workshop soil treated with worms, MMUNW: undiluted motorcar mechanic workshop soil without worms, MMDW: diluted motorcar mechanic workshop soil treated with worms, MMDNW: diluted motorcar mechanic workshop soil treated without worms, MCUW: undiluted motorcycle mechanic workshop soil treated with worms, MCUNW: undiluted motorcycle mechanic workshop soil without worms, MCDW: diluted motorcycle mechanic workshop soil treated with worms, MCDNW: diluted motorcycle mechanic workshop soil treated without worms

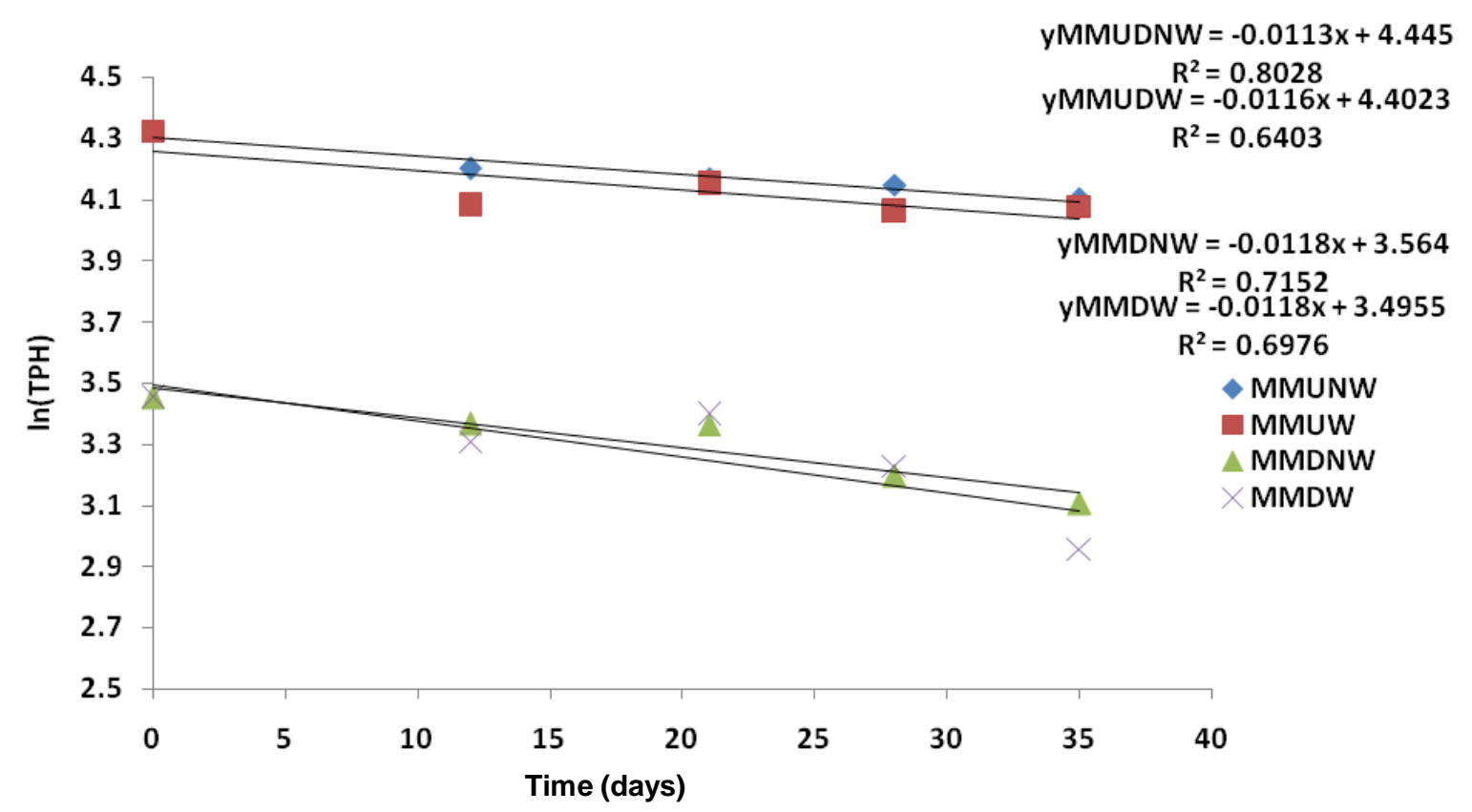

Figure 1. Effect of earthworm innoculation on the bioremediation kinetics of petroleum hydrocarbon contaminated soil from motorcar mechanic workshop.

$100 \%$ death of the worms in less than $24 \mathrm{~h}$. It was expected to have very similar bioremediation rate with the control (MCUNW) since all the worms died within $24 \mathrm{~h}$ after introduction. Table 1 confirmed this as percentage drop in TPH for MCUW and MCUNW which was found to be 24.26461 and 24.56509 , respectively. MMUW recorded an earthworm survival rate of $30 \%$ at the end of the study (35 days) and also recorded a slightly higher TPH drop than the control ( 36.35 and 34.97 , respectively). The death of the worms may be as a result of any or a combination of the following reasons: intolerable levels of petroleum hydrocarbon contamination, the $\mathrm{pH}$, intolerable levels of heavy metal and carbon black (soot).

The results in Figures 1 and 2 indicate a poor fit to the first order bioremediation kinetics $\left(R^{2}\right.$ generally less than 0.9). However, considering the duration of the study (only 


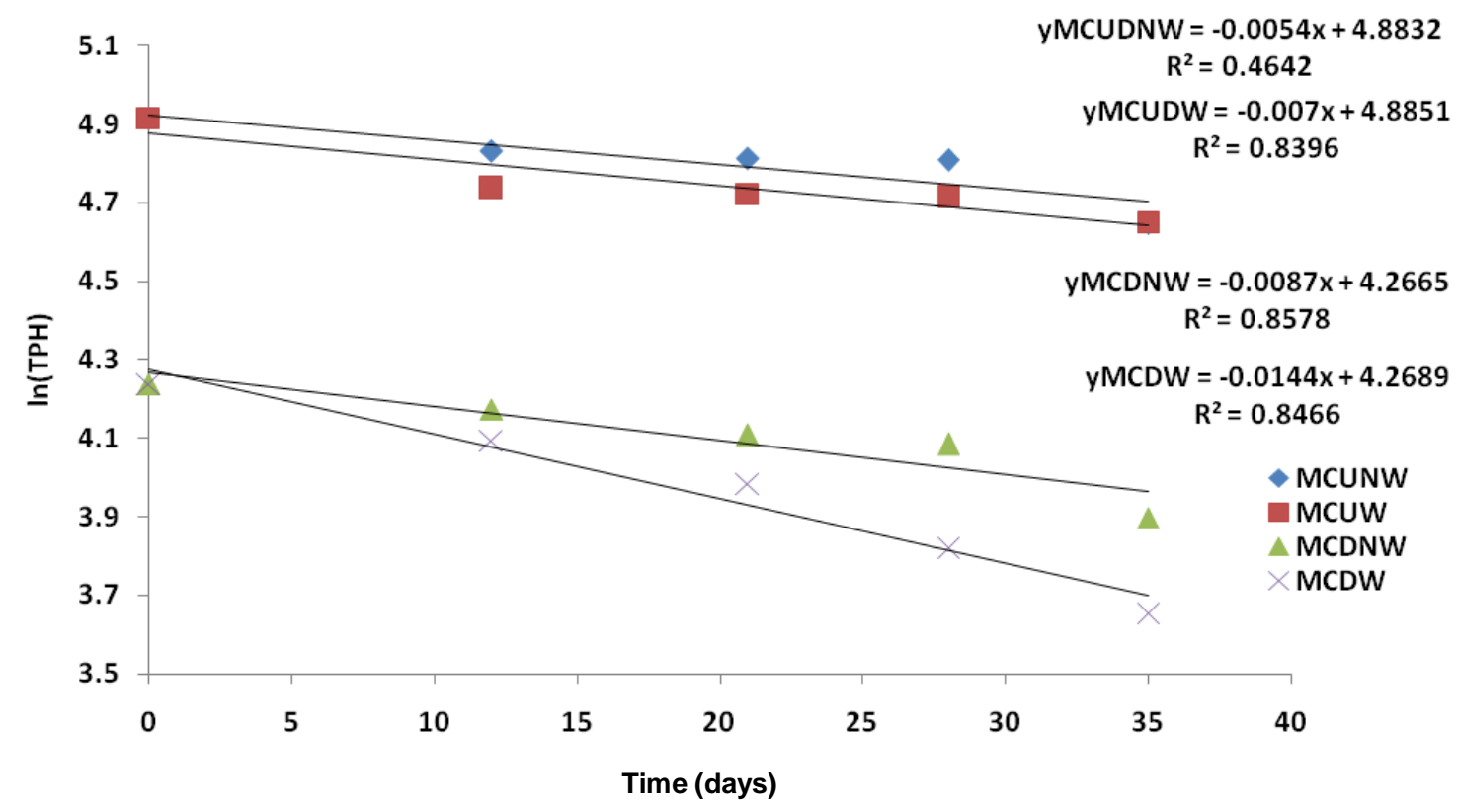

Figure 2. Effect of earthworm innoculation on the bioremediation kinetics of petroleum hydrocarbon contaminated soil from motorcycle mechanic workshop.

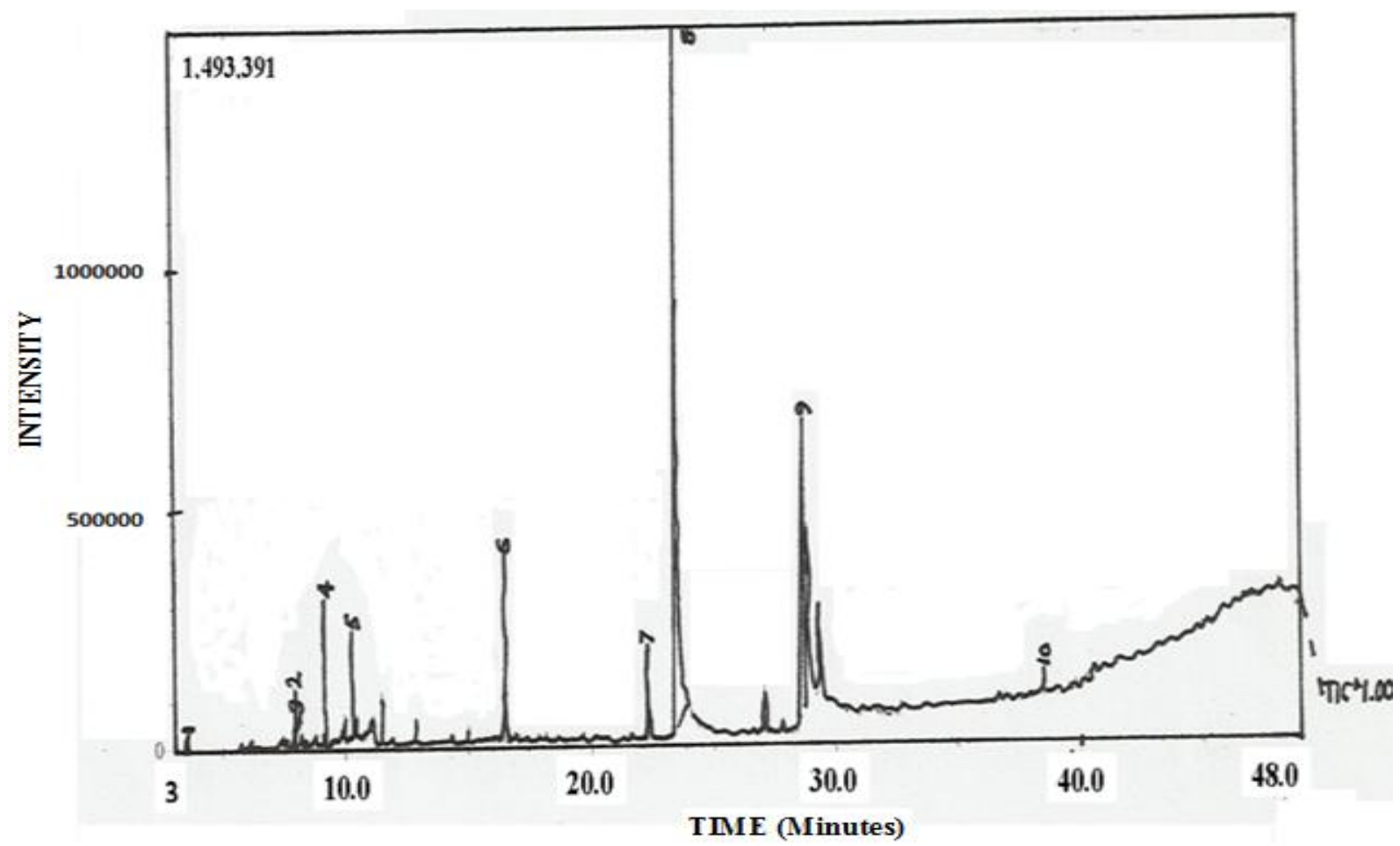

Figure 3. The GC chromatogram of the petroleum hydrocarbon contaminated soil from motorcycle workshop prior to bioremediation (MCO).

35 days) it should be possible to obtain $R^{2}$ value for longer study periods, or some other kinetics may be a better representation of the process.
Based on the result of this investigation, the use of earthworm for the bioremediation of petroleum hydrocarbon contaminated soil from mechanic workshop would 


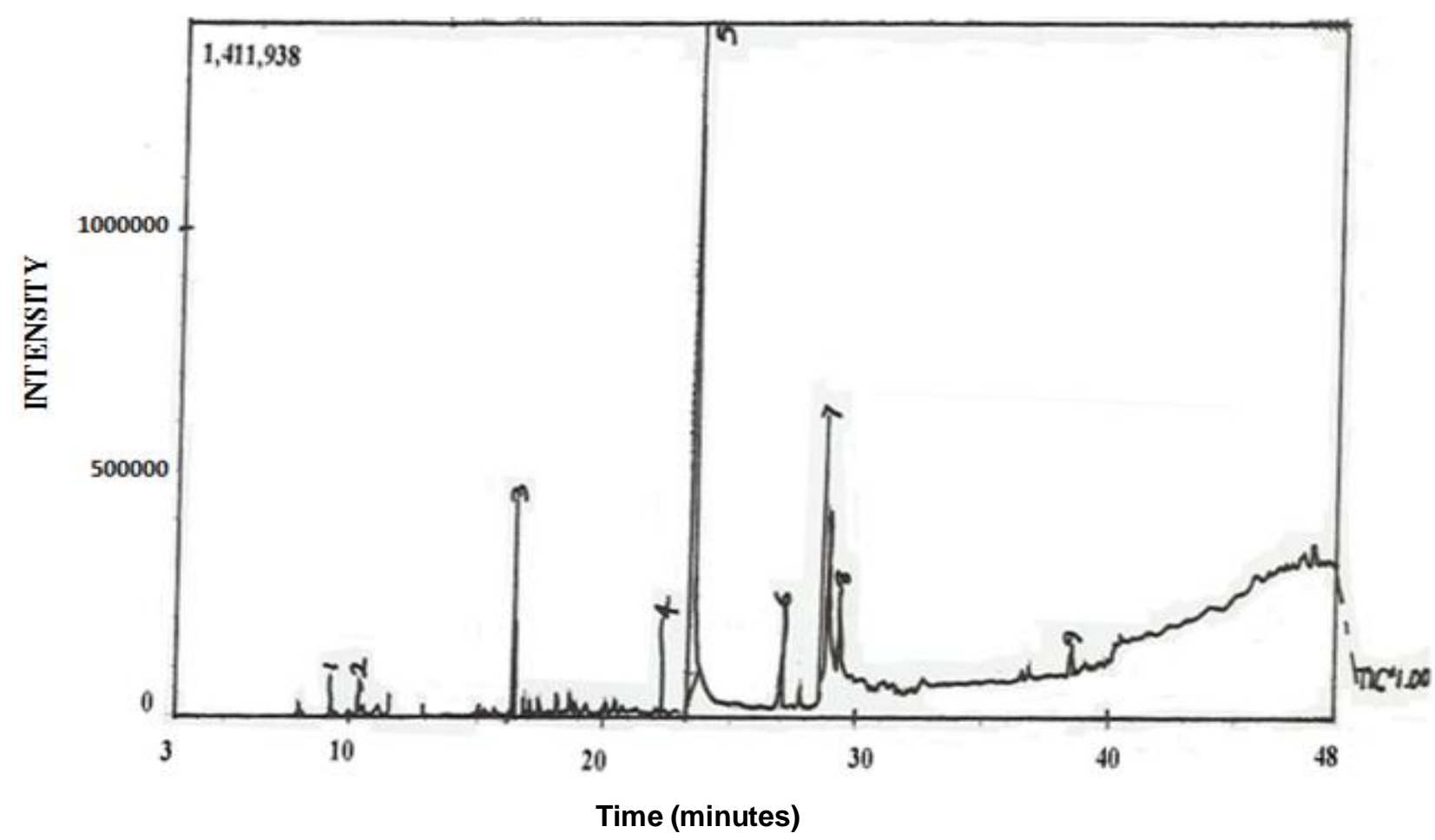

Figure 4. The GC chromatogram of the petroleum hydrocarbon contaminated soil from motorcycle workshop after 35 days of vermin-assisted bioremediation (MC35).

Table 2. Effect of vermin-assisted bioremediation on the composition of petroleum hydrocarbon content of motorcycle mechanic workshop soil.

\begin{tabular}{|c|c|c|}
\hline \multirow{2}{*}{ Hydrocarbon } & MCO & MC35 \\
\hline & \multicolumn{2}{|c|}{ Composition (\%) } \\
\hline C1 - C10 & 3.70 & 6.19 \\
\hline C11 - C20 & 95.47 & 92.31 \\
\hline C20 - C30 & 0.83 & 1.50 \\
\hline
\end{tabular}

Table 3. Effect of vermi-assisted bioremediation on the microbial count and identification of mechanic workshop soil contaminated with petroleum hydrocarbon.

\begin{tabular}{lcccl}
\hline & $\mathbf{1 0 ^ { \wedge } \mathbf { 3 }}$ & $\mathbf{1 0 ^ { \wedge } \mathbf { 4 }}$ & $\mathbf{1 0 ^ { \wedge } 5}$ & Organisms isolated \\
\hline MCDW & TNTC & $3.18^{*} 10^{\wedge} 5$ & $8.15^{*} 10^{\wedge} 5$ & Bacillus sp., Pseudomonas sp. and Staphylococcus sp. \\
MCDNW & TNTC & $3.34^{\star} 10^{\wedge} 5$ & $8.7^{*} 10^{\wedge} 6$ & Bacillus sp., Pseudomonas sp. and Staphylococcus sp. \\
MMDW & TNTC & $4.08^{*} 10^{\wedge} 5$ & $1.21^{*} 10^{\wedge} 6$ & Bacillus sp., Pseudomonas sp. and Staphylococcus sp. \\
MMDNW & TNTC & $3.39^{*} 10^{\wedge} 5$ & $9.4^{*} 10^{\wedge} 6$ & Bacillus sp., Pseudomonas sp. and Staphylococcus sp. \\
MC (Raw) & $5.0^{*} 10^{\wedge} 3$ & $1.0^{\star} 10^{\wedge} 3$ & NIL & Pseudomonas sp. \\
MM (Raw) & $1.19^{*} 10^{\wedge} 4$ & $2.0^{\star} 10^{\wedge} 4$ & NIL & Bacillus sp and pseudomonas sp. \\
\hline
\end{tabular}

TNTC = Too numerous to count, MM (Raw): soil obtained from motorcar mechanic workshop (without organic amendment/earthworms), MC (Raw): soil obtained from motorcycle mechanic workshop (without organic amendment/earthworms) MMDW: diluted motorcar mechanic workshop soil treated with worms, MMDNW: diluted motorcar mechanic workshop soil treated without worms, MCUW: undiluted motorcycle mechanic workshop soil treated with worms, MCDW: diluted motorcycle mechanic workshop soil treated with worms, MCDNW: diluted motorcycle mechanic workshop soil treated without worms. 
Table 4. Effect of vermi-assisted bioremediation on the carbon and nitrogen contents of mechanic workshop soil contaminated with petroleum hydrocarbon.

\begin{tabular}{lcc}
\hline Sample & Nitrogen (\%) & Carbon (\%) \\
\hline MMUW & 0.49 & 11.88 \\
MMUNW & 0.53 & 9.77 \\
MMDW & 0.39 & 4.88 \\
MMDNW & 0.53 & 6.19 \\
MCUW & 0.53 & 11.72 \\
MCUNW & 0.49 & 11.72 \\
MCDW & 0.42 & 8.14 \\
MCDNW & 0.49 & 9.12 \\
\hline
\end{tabular}

MMUW: undiluted motorcar mechanic workshop soil treated with worms, MMUNW: undiluted motorcar mechanic workshop soil without worms, MMDW: diluted motorcar mechanic workshop soil treated with worms, MMDNW: diluted motorcar mechanic workshop soil treated without worms, MCUW : undiluted motorcycle mechanic workshop soil treated with worms, MCUNW: undiluted motorcycle mechanic workshop soil without worms, MCDW: diluted motorcycle mechanic workshop soil treated with worms, MCDNW: diluted motorcycle mechanic workshop soil treated without worms.

Table 5. Elemental analysis of earthworms and soil.

\begin{tabular}{lccccccccc}
\hline \multirow{2}{*}{ Element } & \multicolumn{3}{c}{ Earthworm sample } & \multicolumn{5}{c}{ Soil sample } \\
\cline { 2 - 10 } & REW & MMUW & MMDW & MCDW & UCWS & MMUW & MMDW & MCDW & MCUW \\
\hline $\mathrm{Al}$ & 6.878 & 0.000 & 6.878 & 5.820 & 6.243 & 2.540 & 6.878 & 5.450 & 4.127 \\
$\mathrm{Si}$ & 10.930 & 4.036 & 12.425 & 16.676 & 25.410 & 22.468 & 33.197 & 31.669 & 29.708 \\
$\mathrm{~S}$ & 5.240 & 8.680 & 4.320 & 4.720 & 0.376 & 0.560 & 0.000 & 0.744 & 2.580 \\
$\mathrm{~K}$ & 8.058 & 11.453 & 7.627 & 6.108 & 3.718 & 4.067 & 2.465 & 3.494 & 2.896 \\
$\mathrm{Ca}$ & 8.864 & 17.441 & 8.435 & 6.004 & 4.796 & 8.077 & 1.501 & 1.573 & 3.031 \\
$\mathrm{Ti}$ & 0.689 & 0.276 & 0.893 & 0.743 & 1.031 & 0.803 & 0.566 & 0.893 & 0.605 \\
$\mathrm{~V}$ & 0.030 & 0.0336 & 0.032 & 0.027 & 0.050 & 0.051 & 0.0308 & 0.0437 & 0.026 \\
$\mathrm{Cr}$ & 0.044 & 0.151 & 0.052 & 0.032 & 0.054 & 0.045 & 0.0226 & 0.047 & 0.099 \\
$\mathrm{Mn}$ & 0.085 & 0.070 & 0.147 & 0.132 & 0.093 & 0.077 & 0.058 & 0.108 & 0.148 \\
$\mathrm{Fe}$ & 11.106 & 7.518 & 10.576 & 9.712 & 15.666 & 10.873 & 7.276 & 9.52 & 9.569 \\
$\mathrm{Ni}$ & 0.035 & 0.110 & 0.039 & 0.030 & 0.039 & 0.028 & 0.008 & 0.033 & 0.035 \\
$\mathrm{Cu}$ & 0.066 & 0.104 & 0.058 & 0.036 & 0.061 & 0.064 & 0.013 & 0.053 & 0.058 \\
$\mathrm{Zn}$ & 0.321 & 0.2892 & 0.249 & 0.193 & 0.225 & 0.201 & 0.023 & 0.145 & 0.276 \\
$\mathrm{Ba}$ & 0.251 & 0.269 & 0.215 & 0.134 & 0.305 & 0.430 & 0.000 & 0.260 & 0.134 \\
\hline
\end{tabular}

REW: Earthworm at $\mathrm{t}=0$, before introduction into mechanic workshop soil, MMUW: undiluted motorcar mechanic workshop soil, MMDW: diluted motorcar mechanic workshop soil, MCDW: diluted motorcycle mechanic workshop soil, MCUW: undiluted motorcycle mechanic workshop soil, UCS: petroleum hydrocarbon free soil used in diluting mechanic workshop soil.

be recommended.

From Figures 3 and 4 it may be seen that the numbers of peaks (corresponding to organic components of the contaminating oil) dropped from 10 to 9 . The MS analysis in Table 2 indicated that the C11 - C20 fraction of the contaminating petroleum hydrocarbon was most affected 
by the bioremediation process, dropping from 95.47 to 92.31\%. The C1 - C10 and the C20 - C30 fraction appeared to have increased. For the $\mathrm{C} 1-\mathrm{C} 10$, this may be as a result of the breakdown of C11 - C20 resulting in the formation of more $\mathrm{C} 1-\mathrm{C} 10$, whereas for the $\mathrm{C} 20$ C30 increase may be a result of the reduction in TPH (by bioremediation which primarily affected the C11 - C20), giving the C20 - C30 content an apparent boost.

From the Table 3 , it can be seen that the microbial count of the raw motorcar and motorcycle mechanic workshop soil (MM and MC, respectively) was very low. For instance, at a dilution of $10^{5}$ no microbe was enumerated in both samples. This shows the negative effect petroleum hydrocarbon contamination has on soil microbial community. After amendment with fermented cassava peels with earthworm inoculation (in some samples) microbial activity picked up as shown at the end of the 35 day study.

The microbial count increased by a factor of at least 17 , which is significant. In fact, for $M C$ at dilution of $10^{\wedge} 4$, the count increased by more than 300 times. This increase in microbial count however may not directly be the reason for the reduction in TPH: the samples without worms both indicate slightly higher microbial counts than the corresponding samples with worms though the TPH analysis indicated that the samples with worms recorded lower values of TPH as compared to the corresponding samples without worms. Thus, increased microbial count may have contributed but other factors may have also influenced the TPH of the samples. The microorganisms isolated in all samples were similar: Bacillus sp, Pseudomonas sp and Staphylococcus sp. All these are known to produce biosurfactants of interest for application in petroleum hydrocarbon contaminated sites.

Comparing the results of the diluted samples (MMDW/MMDNW and MCDW/MCDNW) which recorded high earthworm survival in the 35 day study, the trend in the carbon/nitrogen contents followed the same pattern. The carbon and nitrogen contents were lower in the earthworm inoculated samples as compared to the earthworm free samples. Nitrogen is lost mainly through ammonia volatilization or denitrification, The process is performed primarily by heterotrophic bacteria (such as Paracoccus denitrificans and various pseudomonads). Carbon is lost in the form of $\mathrm{CO}_{2}$ during respiration of earthworms/microbes. The results indicate heightened loss of nitrogen and carbon in the earthworm inoculated samples. The observed trend differs from the results of the findings of $\mathrm{Li}$ et al. (2002) which shows that earthworms had no significant influences on nitrogen content. It is possible that the organic amendment (fermented cassava peels) as well as the nature of the soil (contaminated with petroleum hydrocarbon over a long period of time which consequently affected the microbial community) used in the investigation offered a different condition that consequently affected the rate of mineralization of nitrogen.

\section{Metal uptake and elimination}

Elemental analysis of the soil from which the worms were obtained (UCWS) indicated that its iron (Fe) content was higher than that of all mechanic workshop soil considered as shown in Table 5. The composition of all other metals was close to or lower than the values recorded in the mechanic workshop soils. The earthworms prior to introductions into the mechanic workshop soil (REW) showed a high Fe content. The metals of interest were $\mathrm{Zn}, \mathrm{Cu}, \mathrm{Cr}, \mathrm{Ni}, \mathrm{Ti}$ and $\mathrm{Mn}$. Generally, the order of abundance of $\mathrm{Fe}, \mathrm{Mn}, \mathrm{Cu}$ and $\mathrm{Cr}$ as shown in Table 5 (that is $\mathrm{Fe}>\mathrm{Mn}>\mathrm{Cu}>\mathrm{Cr}>\mathrm{Ni}$ ) is similar to that reported by Nwachukwu et al. (2010).

Just as with the simulated used engine oil contaminated soil, there was an appreciable uptake of $\mathrm{Ti}$ and $\mathrm{Mn}$ in both samples that recorded high survival rate of earthworm (MMDW and MCDW). MMUW which recorded a $70 \%$ death rate of the worms however recorded elimination of both $\mathrm{Ti}$ and $\mathrm{Mn}$. This may be because the unfavorable environment affected the feeding behavior of the worms leading to the elimination of these metals. For the metals $\mathrm{Zn}, \mathrm{Cu}, \mathrm{Ni}$ and $\mathrm{Cr}$ which recorded elimination in the study using simulated used engine oil contaminated soil: $\mathrm{Zn}$ recorded a decrease in earthworm body concentration of $\mathrm{Zn}$ for all samples, the concentration of $\mathrm{Zn}$ in the soil from which the worms were obtained was also found to be higher than all mechanic workshop soils considered. This suggests that a relation exist between the body concentration of the metal and the environment where the worms live. The concentration of $\mathrm{Cu}$ was found to be slightly higher in MMUW when compared with the UCWS but lower than MMDW and MCDW. MMDW and MCDW after the 35 day study recorded a drop in earthworm body concentration of $\mathrm{Cu}$ as was recorded in the simulation study. The anomalous behavior with MMUW may again be attributed to unfavorable environment which may have resulted in the preferential excretion of other materials by the worms, resulting in an increased $\mathrm{Cu}$ concentration. A definite relationship between earthworm body concentration and the concentration in the soil cannot be seen from the concentration in $\mathrm{Ni}$ and $\mathrm{Cr}$. Heavy metals uptake/elimination becomes important when earthworms are considered for use in selective removal of metals from contaminated soil or when the possibility of transferring harmful metals down the food chain exist. With this in mind, it is of note that the concentration of the following metals in worms introduced into the following samples increased sharply: $\mathrm{Cr}$, Cu and Ni (MMUW), Mn (MMDW and MCDW).

\section{Conclusions}

The presence of earthworms (E. eugeniae) accelerated the bioremediation of petroleum hydrocarbon contamina- 
ted soil from mechanic workshops. Earthworm survival in the contaminated soil affects the degree to which the worms can influence bioremediation.

\section{ACKNOWLEDGEMENTS}

The authors thank the Science and Technology Education Post-Basic (STEP-B) Innovators of Tomorrow (IOT) and the University Board of Research (Ahmadu Bello University, Zaria) for their financial support.

\section{REFERENCES}

Adams RH, Guzmán-Osorio FJ (2008). Evaluation of land farming and chemico-biological stabilization for treatment of heavily contaminated sediments in a tropical environment. Int. J. Environ. Sci. Tech. 5(2):169-178.

Adesodun JK, Mbagwu JSC (2008). Biodegradation of waste lubricating petroleum oil in a tropical alfisol as mediated by animal droppings. Bioresour. Technol. 99:5659-5665.

Ameh AO, Mohammed-Dabo IA Ibrahim S, Ameh JB, Tanimu Y, Bello TK (2011b). Effect of earthworm inoculation on the bioremediation of used engine oil contaminated soil, Int. J. Biol. Chem. Sci. 6(1):493503.

Ameh AO, Mohammed-Dabo IA, Ibrahim S, Ameh JB, Azienge CD, Yahuza T (2011a). Earthworm survival in used engine oil contaminated soil spiked with manure. Int. J. Biol. Chem. Sci. 5(3):923-929.

Association of Official Analytical Chemists (AOAC) (1990). Official Methods of Analysis, $14^{\text {th }}$ Edition, Washington DC. Arlington, Virginia, USA

Chukwuma MC, Eshett ET, Onweremadu EU, Okon MA (2010). Zinc availability in relation to selected soil properties in a crude oil polluted eutric tropofluvent. Int. J. Environ. Sci. Tech. 7 (2):261-270.

Dhanasekaran D, Thajuddin N, Rashmi M, Deepika TL, Gunasekaran M (2009). Screening of biofouling activity in marine bacterial isolate from ship hull. Int. J. Environ. Sci. Tech. 6 (2):197-202.

Fouépé TA, Kengni TL, Gurunadha Rao VVS, Ndam NJR (2009). Transfer of moisture through the unsaturated zone in the tropical forest using the neutron probe. Int. J. Environ. Sci. Tech. 6 (3):379388.

Hickman ZA, Reid BJ (2008). Earthworm assisted bioremediation of organic contaminants. Environ. Int. 34:1072-1081.

Igwe JC, Abia AA, Ibeh CA (2008). Adsorption kinetics and intraparticulate diffusivities of $\mathrm{Hg}$, As and $\mathrm{Pb}$ ions on unmodified and thiolated coconut fiber. Int. J. Environ. Sci. Tech. 5 (1):83-92.

Nwachukwu MA, Feng H, Alinnor J (2010). Assessment of heavy metal pollution in soil and their implications within and around mechanic villages. Int. J. Environ. Sci. Tech. 7(2):347-358.

Organization for Economic Cooperation and Development (OECD) (2010). Guideline for testing of chemicals, Bioaccumulation in Terrestrial Oligochaetes, No. 317.
Refaat AA (2010). Different techniques for the production of biodiesel from waste vegetable oil. Int. J. Environ. Sci. Tech. 7 (1):183-213.

Schaefer M, Juliane F (2007). The influence of earthworms and organic additives on the biodegradation of oil contaminated soil. Appl. Soil Ecol. 36:53-62.

Schaefer M, Peterson SO, Filser J (2005) Effects of Lumbricus chlorotica and Eisenia fetida on microbial community dynamics in oilcontaminated soil. Soil Biol. Biochem. 37:2065-76.

Shah BA, Shah AV, Singh RR (2009). Sorption isotherms and kinetics of chromium uptake from wastewater using natural sorbent material. Int. J. Environ. Sci. Tech. 6 (1):77-90.

Srivastava S, Thakur IS (2006). Evaluation of bioremediation and detoxification potentiality of Aspergillus niger for removal of hexavalent chromium in soil microcosm, Soil Biol. Biochem. 38:19041911.

USEPA (1996). Recycling Used Oil: What Can You Do? Cooperation Extension Services ENRI-317: 1-2.

Vidali M (2001). Bioremediation: An overview. J. Appl. Chem. 73(7):1163-1172.

Yerushalmi L, Rocheleau S, Cimpoia R, Sarrazin M, Sunahara G, Peisajovich A, Leclair G, Guiot RS (2003). Enhanced bioremediation of petroleum hydrocarbons in contaminated soil. Bioremed. J. 7 (1):37-51.

Yeung PY, Johnson RL, Xu JG (1990). Biodegradation of petroleum hydrocarbons in soil as affected by heating and forced aeration. $J$ Environ. Qual. 26:1511-1576.

Zhang H, Dang Z, Zheng LC, Yi XY (2009). Remediation of soil cocontaminated with pyrene and cadmium by growing maize (Zea mays L.). Int. J. Environ. Sci. Tech. 6 (1):69-76. 